$\Phi=\Phi$

\title{
A description of the guidelines for family members on how to cope and support a person with a head injury
}

\author{
Maria Tegelela Iyambo ${ }^{1 *}$, Louis F Small ${ }^{1}$, Agnes Van Dyk ${ }^{2}$, Esther Kamenye ${ }^{3}$ \\ ${ }^{1}$ School of Nursing and Public Health, University of Namibia Windhoek, Namibia \\ ${ }^{2}$ Department of General Nursing Science, International University of Management (IUM), Windhoek, Namibia \\ ${ }^{3}$ School of Nursing and Public Health, University of Namibia Windhoek, Namibia \\ *Corresponding author E-mail: miyambo51@gmail.com
}

\begin{abstract}
The purpose of this article is to describe the guidelines for the family members on how to cope and support a person with a head injury. A qualitative explorative, descriptive and contextual research design was conducted utilizing individual in-depth face-to-face interview to gather data from family members of a person with a head injury. This study was conducted in three of the northern regions of Namibia, i.e. Oshana, Omusati and Ohangwena. Data was analyzed using Tech's method for content analysis.

The results of this study showed that family members of a person with head a injury had varied and different experiences varying from different feelings, challenges and support to them.

Based on these findings, the guidelines were developed to assist the family members of a person with a head injury on how to cope and support the person with a head injury. These guidelines may be implemented by any family who are taking care of a person with a head injury.
\end{abstract}

Keywords: Guidelines; Rational; Operationalization; Families; Head Injury; Person.

\section{Introduction}

This article is extracted from the authors' study, "The experiences of family members of a person with a head injury".To address the purpose of the study, a research project was conducted, which was qualitative explorative, descriptive and contextual in nature. The main findings of the study showed that family members of a person with a head injury had varied and different experiences varying from different feelings, challenges and support to them.

Head injury is referred to as traumatic brain injury (TBI) or acquired brain injury (ABI) which occurs when a sudden trauma causes damage in the brain (Tidy, 2007).According According to to answers to questions by members of head injury patients, Hutchison and Hutchison (2009) pointed out that head injury may also occur as a result of lack of oxygen, such as during drowning, or as a result of lack of blood supply to the brain, such as following a cardiac arrest. When an adequate force is administered to the head, millions of nerve fibres twist and stretch or may cause the sharing and death of some neurons. This may result in physical, emotional, psychological or behavioral complications (Foulis, 1999). A victim has small or extensive wounds on the head, and physiologic functions may be mildly lost or severely altered (Ursano, Caughey and Fullerton, 1994).When When damage is done to the brain, its effects may be irreversible, or the brain requires time, dedication and a lot of patience, even from medical professionals, to recover (Anon, 2001).

Head injuries are not only challenge to victims alone, but also to family members and the Health Services. Nearly US $\$ 100$ billion is spent annually on hospitalization and lost productivity because of trauma in the United States (USA) alone (Thelan, Lough, Urden, $\&$ Stacy, 2006).
Although the costs spend on head injuries in Namibia are not known, these cannot be less than the costs in developed countries like the USA, because of her under developed services. Family members spend lots of money on hospital bills, transport to and from hospitals and other hidden costs on a hospitalized member, and sometimes have to foot bills for funerals resulting from such injuries. Family members also suffer not only physically, but also psychologically during the time of hospitalisation, bereavement or rehabilitation as they are trying to come to terms with new and difficult changed situations.

Their distorted thoughts and emotions may further be aggravated by disfigured and swollen heads of loved ones who might be lying motionless in a coma or under the influence of sedatives during the first days of hospitalization. The environment of the ICU itself is a strange place. It may be perceived as hostile, formidable, stressful and frightening with its alarming machines (Thelan et al, 2006). Family members go through the "the vigilance" as expressed by Johnson (1998) and want to be with the loved one 24 hours. Many thoughts go through their heads when thinking about the fate of a loved one and what they might have to face.

Under such circumstances, health professionals, especially nurses, who many at times have to deal with family members of head injury patients, need to have an understanding of diverse behavior, which may even be irrational or unacceptable according to hospital rules, and need to exercise a lot of patience to maintain calmness, offer support and keep ordering in the units.

The authors were convinced that is very important to developguidelines that will assist the family members on how to cope and support a person with a head injury. This article presents the descriptions of the guidelines on how to cope and support a person with a head injury. 


\section{Guidelines for family members of a person with a head injury}

\subsection{Guideline 01: facilitating the understanding of the phenomenon head injury to family members}

\subsubsection{Rationale}

The rationale is for the family members of a person with a head injury to acquire the knowledge about the whole phenomenon of head injury and how to live as a person with head injury.

\subsubsection{Operationalization}

Family members have to:

- Request from nurses/doctors relevant information so as to understand the phenomenon of head injury;

- Actively participate in interventions related to the physical and emotional care of a person with a head injury with the guidance from health care providers;

- Observe the person with a head injury for any physical, social, psychological and behavioral deficits and to report early to the health care providers;

- Learn to understand and physically and emotionally support the person with a head injury; and

- Understand and effectively play their role during the rehabilitation period of a person with a head injury.

\subsection{Guideline02: facilitating supporting mechanisms by family members of a person with a head injury}

\section{Rationale}

The rationale is that family members need to identify and develop their own short and long term supporting mechanisms. One support mechanism is the need to develop a positive attitude towards the person with a head injury and towards the condition itself Attitudes influence our thinking and behavior and develop over time through socialization. Attitudes are influenced by a personal or social philosophy and determine the person's willingness to care, support or assist another person (Kozier, Bergman \& Snyder, 2008). Another supporting mechanism is to manage to tolerate the behaviors of the person with a head injury that might be nonresponsive, slow-responsive, aggressive or inappropriate. Family members need to know and understand that recovery from a head injury takes long and needs patience and tolerance - thus patience is an important virtue.

\subsubsection{Operationalization}

Family members have to:

- Ask information from intensive care nurses, religious leaders or community volunteers to put them into contact with persons or support groups of family members of a person with a head injury to assist and support them in the new life facing them of caring for a person with a head injury;

- Ask intensive care nurses to bring them into contact with a skillful person, like a psychiatric nurse, in order for them to discover their personal belief systems and why/how they are going to take care, maybe for a very long time, for the person with a head injury;

- Ask the intensive care nurse to bring them into contact with a social worker or psychiatric nurse or psychologist for a sensitivity session so that they can express all their doubts, fears, misgivings and then, with professional help, try to figure out solutions;

- Identify, utilize and appreciate available social support systems for the care and support for a person with a head injury; and

- Learn and develop tolerance and understanding of the responsibilities in the caring and support of a person with a head injury from an expert, for example, a psychiatric nurse, of support group.

2.3. Guideline 03: facilitating coping mechanisms related to the emotional turmoil affecting family members of a person with a head injury

\subsubsection{Rationale}

When a person experiences a stressful situation that is difficult to understand or adapt to, he/she experiences emotional turmoil because of the many and varied feelings and emotions arising from such a situation. Family members undergo such emotional turmoil as the injury to loved one strikes unexpectedly and threatened effective family functioning.

Therefore, the rationale is that family members need to learn how to cope with such a patient.

\subsubsection{Operationalization}

Family members have to:

- Verbalize their needs to each other and to professional health care providers, like social workers, spiritual leaders, nurses and doctors;

- Critically reflect on and utilize different coping skills they might have and learn and practice new ones, both short-term and long term ones. These coping skills must be based on two dimensions: problem management, (that are directed at changing the stressful situation) and emotional regulation, (including the seeking of social support, venting of feelings, avoidance and denial) (Glanz, Rimer, \& Lewis, 2002).

- Learn and practice positive thinking and living with a person with a head injury; and

- Identify and utilize counseling services available either in health facilities or in their communities.

2.4. Guideline 04: facilitating interventions relating to challenges facing family members of a person with head injury

\subsubsection{Rationale}

Family members are faced with many challenges when an accident occurred, especially when there is a head injury, which could be originating from the external environment or from within. A head injury may cause physical, cognitive, behavioral or social deficits in a person which could pose challenges to family members, and they need to carry out certain activities that the person with a head injury can no longer perform or may perform poorly. The family members may not understand the change in knowledge the person with a head injury previously had, or changed behavior or social interaction, and may thus be powerless or even embarrassed by the person's communication or interactions.

\subsubsection{Operationalization}

Family members have to:

- Ask for assistance to learn how to recognize complications that could occur in the patient and report that to the relevant health care provider.

- $\quad$ Ask intensive care nurses to bring them into contact with a skillful person, like a psychiatric nurse, in order for them to discover their personal belief systems and why/how they are going to take care, maybe for a very long time, for the person with a head injury;

- Ask intensive care nurse to bring them into contact with a social worker or psychiatric nurse or psychologist for a sensitivity session so that they can express all their doubts, fears, misgivings and then, with professional help, try to figure out solutions; 
- Identify, utilize and appreciate available social support systems for the care and support of a person with a head injury; and

- Learn and develop tolerance and understanding of the responsibilities in the caring and support of a person with a head injury from an expert, for example, a psychiatric nurse, and/or a support group.

\subsection{Guideline 05: facilitating constructive interpersonal relationships and effective communication between fam- ily members and health care providers}

\subsubsection{Rationale}

Communication forms the basis of all human relationships and forms the bond of humanness especially in the health care system (Searle, 2008). The rationale is that family members need to communicate all aspects concerning the patient they care for.

\subsubsection{Operationalization}

Family members have to:

- Initiate and strengthen healthy interpersonal skills because these are crucial for the establishment of therapeutic nursefamily members relationship;

- Develop interest in, and sensitivity towards the health care providers;

- Be genuine, real, honest and authentic towards themselves, health care providers and the person with head injury;

- Recognize and correctly interpret non-verbal communication between themselves, health care providers and the person with head injury;

- Cultivate sensitivity towards challenges to the communication process;

- Establish, promote and maintain effective inter-personal communication between themselves, the multi-disciplinary team and the person with head injury; and

- Actively participate in information sharing programs and support group activities.

\section{Competing}

The authors declare that they have no financial or personal relationship(s) which may have inappropriately influence them in writing this article.

\section{References}

[1] Tidy, C. (2007). Comprehensive Information to patients on Head Injury. On line PatientPlus Newspaper, UK. Retrieved September 19, 2009 from http://www.google.com/.

[2] Hutchison, R., Hutchison, M.S. (2009). Frequently Asked Questions about Head Injury. Retrieved on July 20, 2009 from http://hosting.texoma.net/business/biotech/thia-faq.htm.

[3] Foulis, E. (1999). Head Injury. Retrieved on the 11 August 2009 from http://www.unisa.ac.za/contents/public

[4] Ursano, R.J., McCaughey, B.G. \& Fullerton, C.S. (1994). Individual and Community Responses to Trauma and Disaster. Cambridge: Cambridge University Press. https://doi.org/10.1017/CBO9780511570162.

[5] Anon. (2001). Brain Injury.Saskatchewan: Saskatchewan Brain Injury Association Press.

[6] Thelan, L.A., Lough, M.E., Urden, L.D. \& Stacy, K.M. (2006) Critical Care Nursing. Diagnosis and Management. St. Louis: Mosby.

[7] Johnson, G. (1998). Traumatic Brain Injury Survival Guide. Retrieved on the August 27, 2008 from http://www.tbiguide.com.

[8] Kozier, B, Erb, G, Bergman, A \& Snyder, S. (2008). Fundamentals of Nursing.Concepts, process, and practice. Pearson: Prentice Hall

[9] Glanz, K., Rimer, B. K. \& Lewis, F. M. (2002). Health Behavior and Health Education: Theory, Research and Practice. ( $3^{\text {rd }}$ ed). San Francisco: Jossey-Bass.
[10] Searle, C. (2008). Professional Practice - A Southern African Nursing Perspective. ( $4^{\text {th }}$ ed.). Pietermaritzburg: Butterworth Publishers (Pty) Ltd. 